\title{
Ecology of Interstitial Faunal Assemblage from the Beaches along the Coast of Kerala, India
}

\author{
Geetha Priyalakshmi ${ }^{1}$ and N. R. Menon ${ }^{2,3}$ \\ ${ }^{1}$ Department of Zoology, Bharata Mata College, Thrikkakara, Kochi-682021, Kerala, India \\ ${ }^{2}$ School of Marine Science, CUSAT, Kochi-682016, Kerala, India \\ ${ }^{3}$ Nansen Environment Research Centre, Kochi-682016, Kerala, India \\ Correspondence should be addressed to Geetha Priyalakshmi; priyalakshmig@yahoo.co.in
}

Received 11 August 2013; Accepted 25 November 2013; Published 23 January 2014

Academic Editor: Swadhin Behera

Copyright (C) 2014 G. Priyalakshmi and N. R. Menon. This is an open access article distributed under the Creative Commons Attribution License, which permits unrestricted use, distribution, and reproduction in any medium, provided the original work is properly cited.

\begin{abstract}
A quantitative and qualitative study of interstitial fauna and environmental variables was carried out on five selected sandy beaches of the west coast of India. Species of nine interstitial taxa abound the beaches. Nematodes, harpacticoid copepods, turbellarians, and polychaetes constituted the bulk of the population. The available energy in the beaches ranged from 0.2245 to 16.08 joules $/ \mathrm{mg}$ and the grain size varied from 0.93 to $2.88 \varphi$. Organic matter correlated significantly with coarse sand (Pearson correlation $r=$ 0.651; $P<0.01$ ). Organic carbon, particle size, and dissolved oxygen determined the abundance and distribution of interstitial fauna as per multivariate BIOENV analysis. Shannon Wiener $H^{\prime}$ diversity index was maximum at Cherai (2.027) and minimum at Sakthikulangara (1.144) beach. The value of nematode/copepod ratio $(N(2 A) / C>10)$ indicated at Sakthikulangara beach validates the increased sensitivity of harpacticoids to environmental stress.
\end{abstract}

\section{Introduction}

The coastline of Kerala, which extents up to $590 \mathrm{kms}$ is intercepted by fishing harbours, ports, tourist resorts, mangrove beds, sandy beaches, and so forth [1]. Sandy beaches harbour diverse and abundant assemblage of interstitial organisms and the different taxonomic groups have complex distribution patterns [2]. Cyclic sedimentary processes make the beaches of Kerala fragile. A beach, maintained for a particular period, may not remain there forever. The wave climate and the beach processes along the Kerala coast are found to vary considerably in both spatial and temporal frame [3]. Erosion adversely affects the density of intertidal interstitial populations, which live in the interstices of beach sediments. Biodiversity assessment is the key to understand the relationship between biodiversity and ecosystem functioning [4] Hydrodynamics changes the physicochemical sedimentary environment and food availability which are directly related to meiofauna spatial distribution patterns [5]. Meiofauna plays a major role in pollution monitoring studies $[6,7]$.
The meiofaunal species are vulnerable to abiotic and hydrodynamic disturbance [8]. Though arguments were traditionally put forth against the use of meiofauna as biological indicator, underlining difficulties in identification, the high rate of sampling frequency and the microscopic size of the organisms, and new technologies and tools, such as standardized methodologies, electronic identification keys, molecular approaches, and the creation of new indices, currently allow for and promote the use of meiofauna in ecological studies [9]. Though several meiofaunal studies have been conducted on the west coast of India [10-16], there is scanty information on the ecology and taxonomy of interstitial fauna from the sandy beaches of Kerala. Further, ecological studies of meiofauna are necessary to understand the trophodynamics of sandy beaches. Although a great deal of uncertainty remains in our understanding of meiofaunal biodiversity, ecology, and evolutionary biology, this area of research remains among the most challenging, the most neglected, and potentially the most enlightening frontiers of discovery in biology [17]. 


\section{Materials and Methods}

\subsection{Study Area}

Study Area. Five sandy beaches (Figure 1) such as Cherai (lat. $10^{\circ} 09^{\prime} \mathrm{N}$; long. $76^{\circ} 02^{\prime} \mathrm{E}$; St.1), Fort Kochi (lat. $9^{\circ} 18^{\prime} \mathrm{N}$; long. $76^{\circ} 05^{\prime} \mathrm{E}$; St.2), Arthungal (lat. $9^{\circ} 10^{\prime} \mathrm{N}$; long. $76^{\circ} 23^{\prime} \mathrm{E}$; St.3), Sakthikulangara (lat. $8^{\circ} 45^{\prime} \mathrm{N}$; long. $76^{\circ} 38^{\prime} \mathrm{E}$; St.4), and Veli (lat. $8^{\circ} 29^{\prime} \mathrm{N}$; long. $76^{\circ} 59^{\prime} \mathrm{E}$; St.5) located along the coast of Kerala, India, were identified by site survey to undertake a study of the psammophilous fauna. Cherai and Arthungal beaches are relatively stable and less disturbed. Fort Kochi and Veli beaches are affected by industrialization and Sakthikulangara is characterized by natural radioactive pollution of thorium and presence of large quantities of faecal waste. Seasonal collections were made for one year (2005-06). Samples were collected at two points (100 $\mathrm{m}$ apart) along a transect from the subtidal area of each beach by using a galvanized iron core of $8 \mathrm{~cm}$ inner diameter. Three undisturbed sediment samples each were immediately transferred into bottles. $7 \% \mathrm{MgCl}_{2}$ prepared in filtered sea water was added to the sediment sample to anaesthetize the animals. The samples were preserved in buffered $4 \%$ formalin prepared with filtered seawater. $0.1 \%$ Rose Bengal [18] was added to the sample for efficient extraction of the fauna. Meiofauna was separated by suspensiondecantation method [19] with a few modifications [20].

2.2. Granulometry. Sediment samples of approximately 150 gms were used from each station for carbon analysis and textural analysis. Sediment was subjected to repetitive rinsing and decanting employing distilled water to remove the salinity and then dried in an oven under a temperature of $40-50^{\circ} \mathrm{C}$. The percentage of organic carbon was estimated with a $\mathrm{CHN}$ analyzer (Elementar Vario III) and the organic carbon values were converted to organic matter using a conversion factor of 1.72 [21]. Energy content was obtained using the method adopted by Barnes [22].

Dry sieving method [23] was followed for the textural analysis of the sediment sample, since the beach sand contained less than $5 \%$ silt-clay fraction. The equipment for the analysis consisted of a stacked set of Wentworth grade sieves with. 5 phi $(\varphi)$ intervals within the range of $62-2000 \mu$. $80 \mathrm{gm}$ of oven dried salt free sand sample was introduced into the $2000 \mu$ sieve at the top of the stack and the stack transferred to the mechanical shaker and agitated for 15 minutes. After this, the material in each sieve was taken and weighed. Material $(<62 \mu \mathrm{m})$ that had fallen into the pan at the bottom of the sieve stack was also weighed. Fraction of the sediment (calculated in percentage weight of the total sample) was transferred into cumulative frequency series and then plotted as cumulative frequency curve. From the resulting sigmoid curve, the particle diameter was estimated and interpreted. From the cumulative frequency curve, graphic mean and standard deviation were calculated [24]. The nature of sediment was identified based on the verbal classification measure of Folk [24].

2.3. Hydrography. Interstitial water was siphoned out from the pit that was made by the core sampler employed to collect

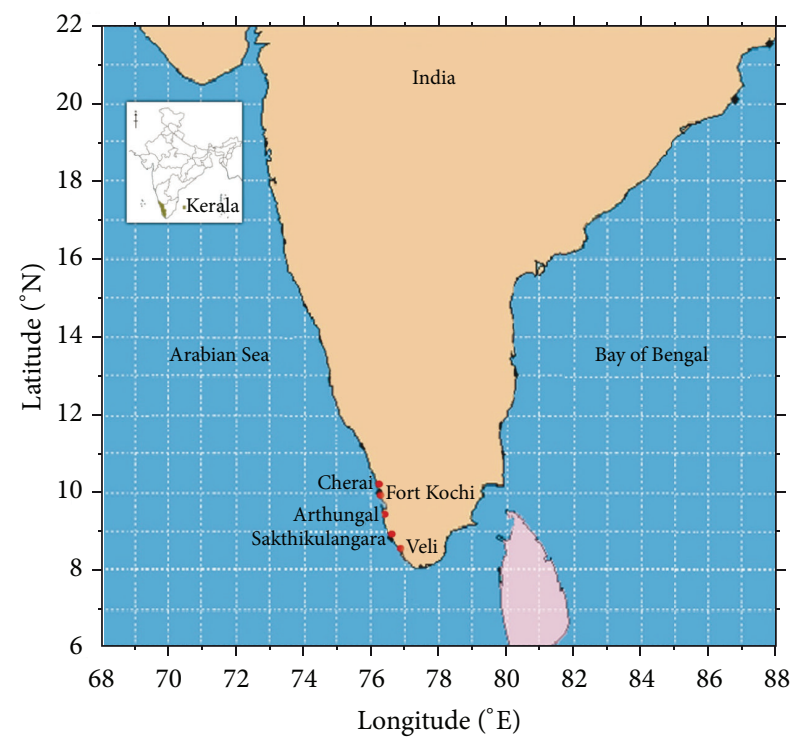

FIGURE 1: Sampling locations of the study area.

the sediment. These samples were analysed for temperature (with a high precision mercury thermometer), salinity (using a calibrated salinometer), $\mathrm{pH}$ (with Pocket $\mathrm{pH}$ Tester, Eutech) and dissolved oxygen by Winkler's method[25].

\subsection{Ecological Indices}

Diversity Indices. Species diversity was estimated according to Shannon-Wiener $H^{\prime}(\log 2)$ [26]), Margalef's richness $(d)$, [27] and Pielou's evenness $\left(J^{\prime}\right)$ [28] indices. The nematodecopepod $N(2 A) / C$ ratio was calculated by dividing the number of nematodes ( $2 A$ trophic group or epigrowth feeders) in a sample by the number of copepods [29].

2.5. Statistical Analysis. The software programmes namely, SPSS (Version 11.0) and PRIMER V6 (Plymouth Routines In Multivariate Ecological Research, Version 6) were used for univariate and multivariate analysis of data. Pearson productmoment correlations were performed to test the relationship between meiofaunal distributions and environmental variables. Correlations were considered significant at $P<0.01$.

BEST Analysis. The BEST routine available in PRIMER v6 combines the BIO ENV and BV STEP procedures of PRIMER v5. This routine uses all the available environmental variables to find out the combination that "best explains" the patterns in the biological data. PRIMER v6 for windows was used for the analysis of community structure.

Similarity Indices. Multivariate analysis consisted of estimating Bray-Curtis similarity after suitable transformation of sample abundance data. The similarity matrix was subjected to both clustering (hierarchical agglomerative method using group average linking) and ordination (nonmetric multidimensional scaling, MDS) using PRIMER v6. The significance 
of the clusters formed was tested by the similarity profile (SIMPROF) test.

\section{Results and Discussion}

In marine benthic ecology, sediment granulometry, along with environmental parameters is considered essential to determine the composition and characterization of benthic organisms [30]. The sediment characteristics and the interstitial faunal density are presented in Tables 1 and 2 , respectively. The nature of sediments varied from very well sorted to moderately sorted. Moderately well sorted medium sand harbours the most diverse meiofauna [9]. Coarser grains have small retention capacity than fine ones, but, on the other hand, they have larger capacity of circulation [31]. Therefore, any major change in the sedimentary structure results in a change in the community structure [32]. Absence of meiofaunal taxa in post-monsoon at Fort Kochi beach (Table 2) accompanied by a drastic reduction in the medium sand fraction percentage corroborates the statement.

But a single factor alone cannot be held responsible for meiofaunal reduction. The pore volume in poorly sorted sediments is often reduced to $20 \%$. The poor sorting of sediments at Sakthikulangara beach (Table 1) implies that the transportation agencies were incapable of separating the sediments into different class sizes and differential settling rates may be prevalent in the area. The sandy beaches of Kerala are subjected to seasonal erosion and accretion. Due to various oceanographic phenomena like upwelling and storm surges accompanied by the south west and north east monsoon, the morphology, beach profile, and the physical characteristics of the beaches alter drastically [3]. The variations noticed in the textural characteristics of the beach sediment are due to the physical changes that happen to these sandy beaches periodically.

Besides texture, organic content of sediment is an important factor that determines the infaunal distribution, since it is a dominant source of food, directly for deposit feeders and indirectly for suspension feeders. It is generally believed that sediments with coarse particles are deficient in organic matter whereas fine grain sediments show organic enrichment [30]. However, organic matter correlated significantly with coarse sand (Pearson correlation $r=0.651 ; P<0.01$ ) at the studied locations. Unlike the earlier findings that coarse sediments contain lesser organic carbon than fine sediments [33], the present study revealed that the angularity of sediments could play a significant role in the amount of organic carbon adsorbed to the sediments. More angular sand particles can harbor more carbon than smooth grains $[9,34]$. Consumption of organic matter bound sediments and subsequent generation of faecal pellets will alter the mechanical composition of sediments. The amount of energy available in different beaches during the period of study ranged from 0.2245 to 16.08 joules/mg (Figure 2). A significant relation was not evident between organic carbon and the numerical abundance of interstitial organisms (Table 4). Ansari and Parulekar could not observe any consistent pattern between organic carbon

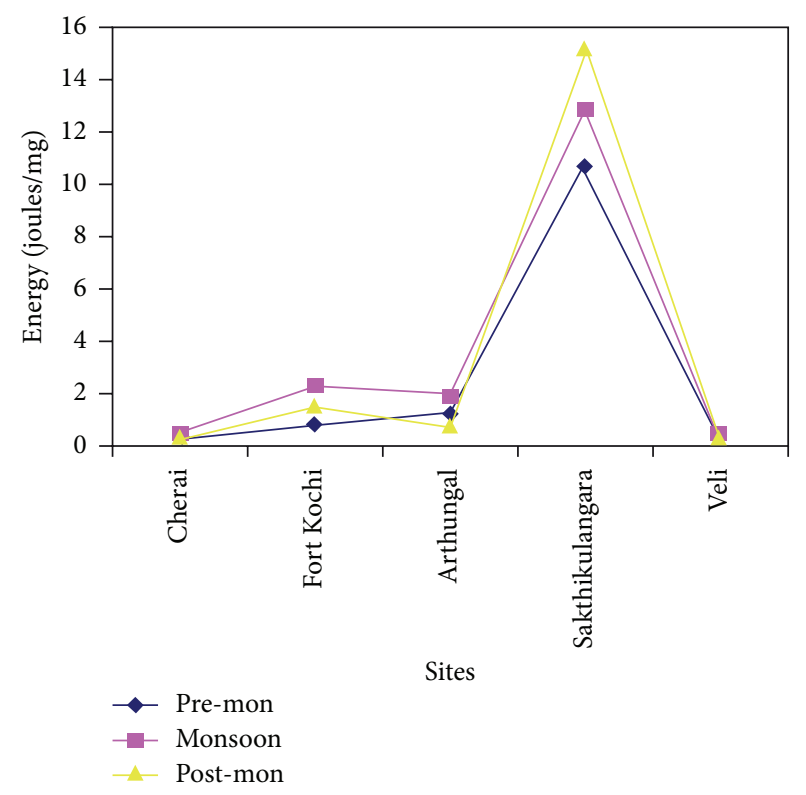

FIGURE 2: Energy content (joules/mg) of the sediment at the different beaches.

and benthic biomass [15]. It is therefore clear that the quality of organic matter matters.

The hydrographic parameters such as temperature, $\mathrm{pH}$, salinity, and dissolved oxygen are presented in Table 3 . The fluctuations in temperature of the interstitial water medium are not very significant in tropical habitats and a temperature fluctuation of $5^{\circ} \mathrm{C}$ is easily endured by the interstitial animals [35]. Of the several hydrographic parameters of the medium that influence the occurrence and distribution of the interstitial forms, salinity is by far the most important in a tropical habitat. An important feature of the study area is the influence of south west monsoon, which affects the hydrographic condition in a remarkable manner. Wide fluctuations in salinity exert great stress upon interstitial organisms. Low salinity characterized Fort Kochi beach (Table 3).

The beach here is narrow and the lower salinity is due to the proximity of the channel leading to the backwaters and the consequent mixing with brackish water [36]. The inflow of fresh water greatly affects the interstitial fauna inhabiting the area. Increased salinity is favourable to harpacticoids [37]. Low salinity at Fort Kochi beach is marked by the absence of harpacticoids in the monsoon and post-monsoon seasons of the year (Tables 2 and 3). Great reduction of meiofauna abundance has been recorded during periods with reduced salinity, after heavy rain [10,38]. In tropical beaches, although the seasons are not markedly delineated, periods of "good weather" and "storms" influence vertical migration of meiofauna [39]. In the marine biome, $\mathrm{pH}$ plays only a minor role for interstitial fauna, since the slightly alkaline sea water is well buffered against $\mathrm{pH}$ fluctuation. Dissolved oxygen of the interstitial water ranged from 3.68 to $8.05 \mathrm{mg} / \mathrm{L}$. Dissolved oxygen in a sandy beach is dependent on the drainage of capillary water and the evaporation of interstitial water in the surface layers. Several reports are available on the correlation 
TABLE 1: Distribution of sand grains in weight percentage (coarse, medium, and fine sand) and sediment characteristics in the study area.

\begin{tabular}{|c|c|c|c|c|c|c|c|c|c|}
\hline \multirow{2}{*}{ Season } & \multirow{2}{*}{ Station } & \multicolumn{3}{|c|}{ Sand fraction wt.\% } & \multicolumn{2}{|c|}{ Mean } & \multirow{2}{*}{ Std. Dev. } & \multirow{2}{*}{ Org. C\% } & \multirow{2}{*}{ Nature of sediment } \\
\hline & & Coarse & Medium & Fine & $\varphi$ & & & & \\
\hline \multirow{5}{*}{ Pre-monsoon } & Cherai & 7 & 75 & 18 & 1.68 & $(310)$ & 0.47 & 0.065 & Well sorted \\
\hline & Fort Kochi & 3 & 80 & 17 & 1.70 & $(320)$ & 0.45 & 0.195 & Well sorted \\
\hline & Arthungal & 48 & 48 & 4 & 0.97 & $(493)$ & 0.76 & 0.300 & Moderately sorted \\
\hline & Sakthikulangara & 34 & 20 & 46 & 1.88 & $(280)$ & 1.19 & 2.85 & Poorly sorted \\
\hline & Veli & 4 & 84 & 12 & 1.65 & $(330)$ & 0.38 & 0.085 & Well sorted \\
\hline \multirow{5}{*}{ Monsoon } & Cherai & 16 & 64 & 20 & 1.62 & $(290)$ & 0.58 & 0.095 & Moderately well sorted \\
\hline & Fort Kochi & 2 & 50 & 48 & 2.19 & $(220)$ & 0.47 & 0.58 & Well sorted \\
\hline & Arthungal & 20 & 53 & 27 & 1.67 & $(320)$ & 0.75 & 0.485 & Moderately sorted \\
\hline & Sakthikulangara & 46 & 30 & 24 & 1.14 & $(430)$ & 1.16 & 3.44 & Poorly sorted \\
\hline & Veli & 1 & 62 & 37 & 2.08 & $(280)$ & 0.54 & 0.095 & Moderately well sorted \\
\hline \multirow{5}{*}{ Post-monsoon } & Cherai & 25 & 60 & 15 & 1.44 & $(400)$ & 0.64 & 0.07 & Moderately well sorted \\
\hline & Fort Kochi & 1 & 3 & 96 & 2.88 & $(140)$ & 0.19 & 0.40 & Very well sorted \\
\hline & Arthungal & 16 & 77 & 7 & 1.42 & $(365)$ & 0.45 & 0.175 & Well sorted \\
\hline & Sakthikulangara & 46 & 25 & 29 & 1.40 & $(440)$ & 1.22 & 4.07 & Poorly sorted \\
\hline & Veli & 12 & 71 & 17 & 1.62 & $(330)$ & 0.49 & 0.065 & Well sorted \\
\hline
\end{tabular}

${ }^{*}$ Particle size in microns.

TABLE 2: Major groups of meiofauna from the study area (density/100 cc).

\begin{tabular}{|c|c|c|c|c|c|c|c|c|c|c|}
\hline Season & Station & Nem & Poly & Oligo & Turb & Hrpc & Gastro & Kinor & Isop & Cnid \\
\hline \multirow{5}{*}{ Pre-monsoon } & Cherai & 343 & 4 & 9 & 116 & 46 & 7 & 3 & 0 & 0 \\
\hline & F. Kochi & 600 & 348 & 0 & 114 & 950 & 695 & 0 & 0 & 0 \\
\hline & Arthungal & 238 & 120 & 0 & 6 & 153 & 0 & 0 & 0 & 2 \\
\hline & Sakthi & 28 & 2 & 0 & 4 & 0 & 0 & 0 & 0 & 0 \\
\hline & Veli & 19 & 2 & 0 & 18 & 48 & 2 & 0 & 3 & 0 \\
\hline \multirow{5}{*}{ Monsoon } & Cherai & 212 & 222 & 92 & 61 & 21 & 0 & 0 & 0 & 0 \\
\hline & F. Kochi & 16 & 0 & 0 & 118 & 0 & 0 & 0 & 0 & 0 \\
\hline & Arthungal & 146 & 43 & 0 & 70 & 4 & 0 & 0 & 0 & 0 \\
\hline & Sakthi & 1006 & 74 & 0 & 123 & 9 & 0 & 0 & 0 & 0 \\
\hline & Veli & 69 & 0 & 0 & 50 & 14 & 0 & 0 & 0 & 0 \\
\hline \multirow{5}{*}{ Post-monsoon } & Cherai & 1191 & 17 & 19 & 233 & 160 & 586 & 290 & 246 & 20 \\
\hline & F. Kochi & 40 & 0 & 0 & 13 & 0 & 2 & 0 & 0 & 0 \\
\hline & Arthungal & 483 & 27 & 22 & 66 & 910 & 5 & 366 & 996 & 0 \\
\hline & Sakthi & 139 & 50 & 0 & 38 & 14 & 0 & 0 & 0 & 0 \\
\hline & Veli & 70 & 0 & 0 & 56 & 139 & 78 & 0 & 0 & 0 \\
\hline
\end{tabular}

Sakthi: Sakthikulangara; Nem: nematode; Poly: polychaete; Oligo: oligochaete; Turb: turbellarian; Hrpc: harpacticoid copepod; Gastro: gastrotrich; Kinor: Kinorhyncha; Isop: isopod; Cnid: cnidarian.

between the meiofaunal abundance and dissolved oxygen $[40,41]$.

Beaches are highly dynamic ecosystems and the study of meiofauna in beach ecology is important for the understanding of trophodynamic processes [42]. The relative abundance of interstitial organisms (annual mean) in different beaches is illustrated in Figure 3. While nematodes were the most abundant taxon in Cherai and Sakthikulangara beaches, the rest of the beaches under study were dominated by harpacticoid copepods. Other groups included turbellarians, polychaetes, oligochaetes, gastrotrichs, isopods, Kinorhyncha, and cnidarians. It could be seen that the distribution of total interstitial fauna and the different taxa was by no means uniform and the order of domination of taxa varied with beaches.

The Pearson correlation matrix between the various meiofauna taxa and the environmental variables is presented in Table 4 . Total meiofaunal density is positively correlated with medium sand at 5\% level of significance. Harpacticoids and turbellarians correlated at 0.05 levels with medium sand.

Rodríguez et al. [8] found that exposure time, desiccation, availability of food, sediment granulometry, tidal zonation, and interstitial water quality are the physical parameters that regulate the abundance of intertidal meiofauna. A multitude of environmental factors shape the meiofaunal abundance 
TABLE 3: Temperature, pH, salinity, and dissolved oxygen content of the interstitial seawater of the study area.

\begin{tabular}{|c|c|c|c|c|c|}
\hline Season & Station & Temp. ${ }^{\circ} \mathrm{C}$ & $\mathrm{pH}$ & Sal. $\%_{0}$ & $\mathrm{DO} \mathrm{mg} / \mathrm{L}$ \\
\hline \multirow{5}{*}{ Pre-monsoon } & Cherai & 26 & 7.05 & 34 & 5.75 \\
\hline & Fort Kochi & 29 & 8.45 & 30.5 & 3.74 \\
\hline & Arthungal & 29 & 7.85 & 36 & 4.89 \\
\hline & Sakthikulangara & 28.5 & 7.85 & 32.5 & 3.70 \\
\hline & Veli & 29.5 & 7.40 & 30.5 & 7.92 \\
\hline \multirow{5}{*}{ Monsoon } & Cherai & 26.75 & 7.95 & 27.5 & 4.18 \\
\hline & Fort Kochi & 27.75 & 8.10 & 19.25 & 4.26 \\
\hline & Arthungal & 27.25 & 7.85 & 28.75 & 3.68 \\
\hline & Sakthikulangara & 24.25 & 7.95 & 25 & 4.30 \\
\hline & Veli & 27.50 & 8.05 & 22 & 8.05 \\
\hline \multirow{5}{*}{ Post-monsoon } & Cherai & 28 & 7.85 & 30.5 & 6.70 \\
\hline & Fort Kochi & 29 & 7.85 & 24.5 & 6.04 \\
\hline & Arthungal & 28 & 7.95 & 32 & 6.53 \\
\hline & Sakthikulangara & 26 & 7.75 & 35.5 & 5.70 \\
\hline & Veli & 29 & 7.75 & 32 & 5.99 \\
\hline
\end{tabular}

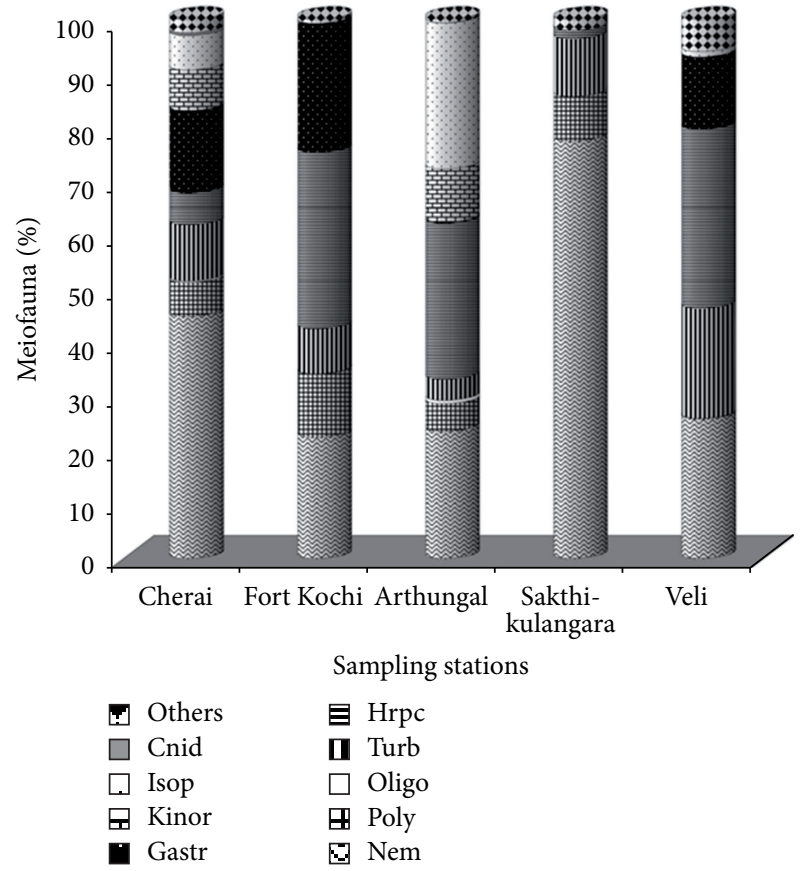

FIGURE 3: Relative abundance (annual mean) of meiofauna taxa in the study area.

and distribution of a habitat. BEST analysis was done to find the best possible combination of variables that determined the faunal abundance and distribution. Biota-Environmental matching (BEST), as per the primer analysis (Figures 4 and 5), showed that organic carbon, particle size, and dissolved oxygen were the best combination of variables that determined the abundance and distribution of interstitial fauna in the present study.

Species diversity was estimated according to the Shannon-Wiener $H^{\prime}(\log 2)$ diversity, Margaleff richness $(d)$, and Pielou's evenness $\left(J^{\prime}\right)$ indices (Table 5).

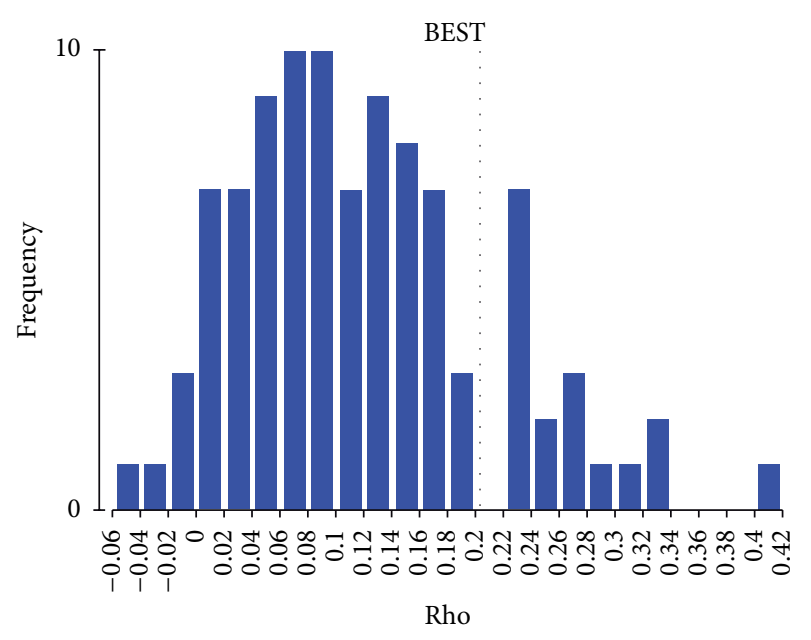

FIGURE 4: Histogram showing the BEST results of the distribution of interstitial fauna based on sediment parameters $($ Rho $=0.202)$.

Shannon diversity index was maximum (2.027) at Cherai and lowest at Sakthikulangara (1.144). Richness was at its peak in Cherai (0.988) and lowest in Sakthikulangara beach (0.599). The evenness component $\left(J^{\prime}\right)$ varied in conformity with $H^{\prime}$. Multivariate analysis consisted of estimating BrayCurtis similarity after suitable transformation of sample abundance data. The similarity matrix was subjected to both clustering (hierarchical agglomerative method using group average linking) and ordination (nonmetric multidimensional scaling, MDS). MDS plot gave a good ordination with a stress value of 0.08 (Figure 6). Significant differences are observed in the distribution of taxa between beaches.

The nematode-copepod ratio was first used by Raffaelli and Mason [43] as a fast and reliable tool in monitoring the level of organic pollution. Despite several criticisms on this simplified relationship [44-46], several researchers [47-50] still use nematode-copepod ratio in assessing and identifying 


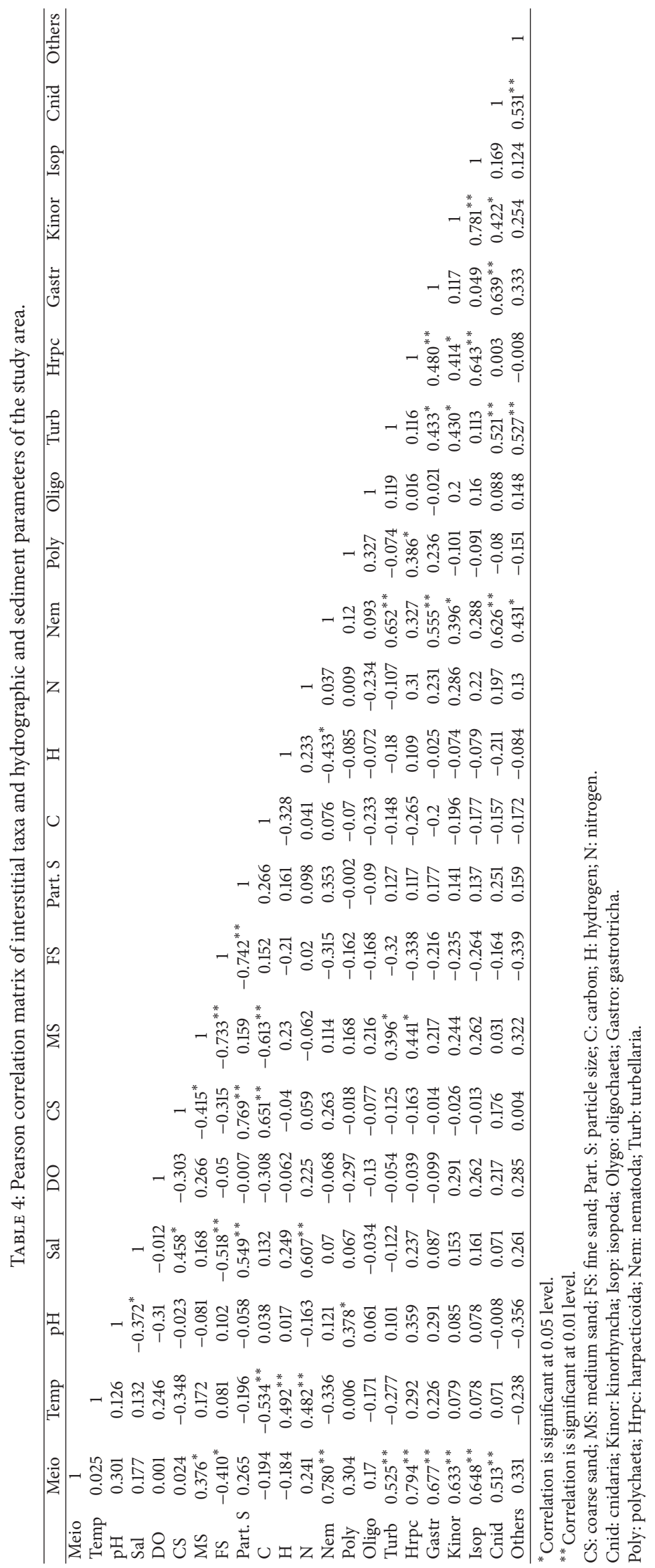


TABLE 5: Diversity indices (annual mean) of total interstitial fauna of the five beaches.

\begin{tabular}{lccc}
\hline Beach & $\begin{array}{c}\text { Margaleff } \\
\text { richness } \\
d\end{array}$ & $\begin{array}{c}\text { Pielou's } \\
\text { evenness } \\
J^{\prime}\end{array}$ & $\begin{array}{c}\text { Shannon Wiener's } \\
\text { diversity index } \\
H^{\prime}(\log 2)\end{array}$ \\
\hline Cherai & 0.988 & 0.695 & 2.027 \\
Fort Kochi & 0.619 & 0.672 & 1.375 \\
Arthungal & 0.786 & 0.681 & 1.751 \\
Sakthikulangara & 0.599 & 0.567 & 1.144 \\
Veli & 0.821 & 0.799 & 1.874 \\
\hline
\end{tabular}

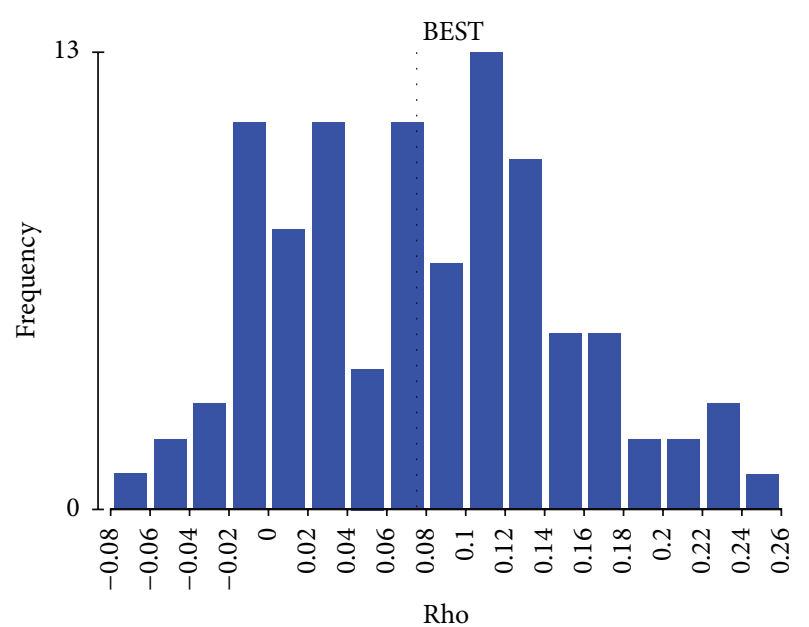

FIGURE 5: Histogram showing the BEST results of the distribution of interstitial fauna based on hydrographic parameters $(\mathrm{Rho}=0.075)$.

eutrophically enriched or polluted sediments. Benthic harpacticoid copepods are known to be sensitive to sediment metal concentration [51]. The nematode/copepod ratio [43] with modifications $[29,52]$ was used as an index to monitor pollution of selected beaches. Warwick [29], based on his studies, has suggested that an indication of pollution might be given by ratios around $40(N(2 A) / C)$ for fine sediments and 10 for sands. The $N(2 A) / C$ ratio value of around 12 indicated at Sakthikulangara beach (Figure 7) is indicative of some disturbance of this beach.

Sakthikulangara beach is characterized by natural radioactive pollution by thorium (based on secondary data) and faecal waste disposal. Smol et al. [54] have reported higher percentage of nematodes and lower percentage of harpacticoids within the sewage $\left(\mathrm{TiO}_{2}\right)$ dumping area of Dutch coast. Ansari et al. [55] also found that copepods are more sensitive to environmental stress than nematodes in their study of interstitial fauna of the shelf region of south east coast of India. Though pollution tests have not been conducted and $\mathrm{N} / \mathrm{C}$ value cannot be taken as a sole means of indicator of pollution, various features observed and analysed during the course of this study depict a different scenario of Sakthikulangara beach.

The assessment of ecological role and the spatial and temporal changes of meiobenthos can be used in environmental monitoring programs whose main goal is often to identify

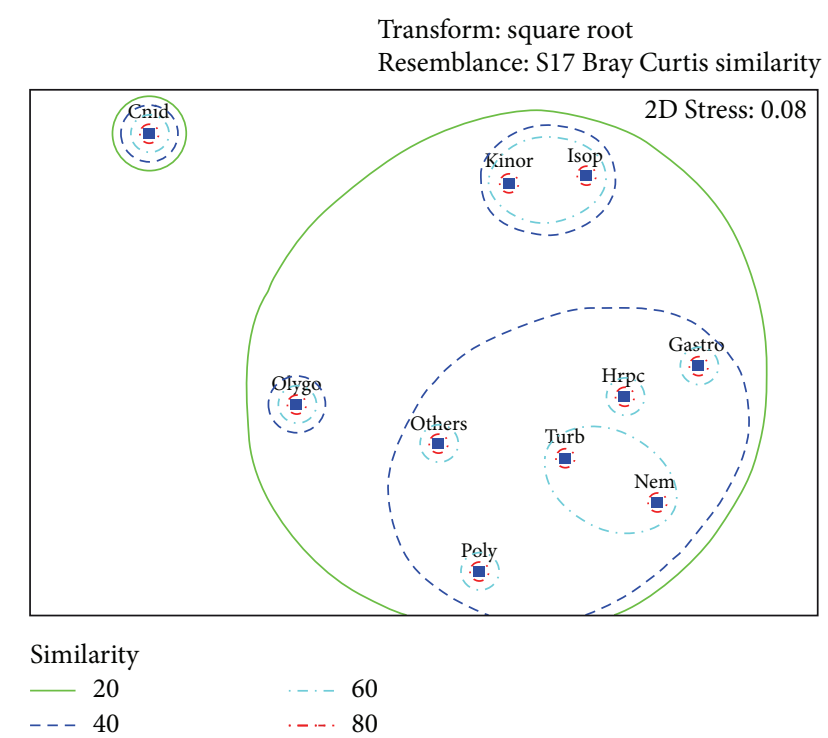

FIGURE 6: Nonmetric multidimensional scaling (MDS) ordination plot (stress $=0.08$ ) of interstitial taxa. (Cnid: cnidaria; Kinor: kinorhyncha; Isop: isopoda; Olygo: oligochaeta; Gastro: gastrotricha; Poly: polychaeta; Hrpc: harpacticoida; Nem: nematoda; Turb: turbellaria).

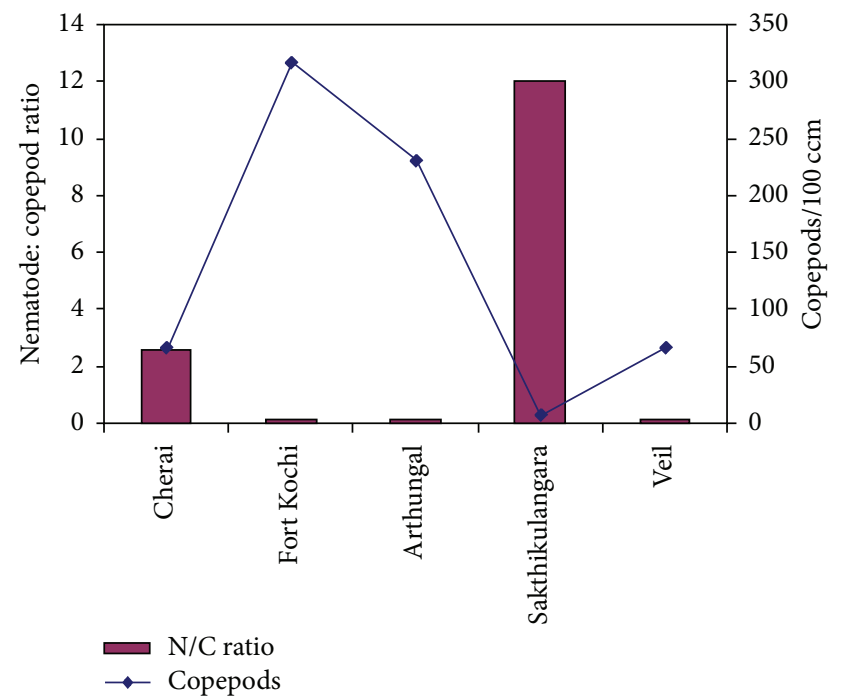

FIgURE 7: Nematode to copepod ratio (bars) and the mean number of harpacticoid copepods (line) over the range of beaches sampled. The three divisions of the graph were proposed by Lee et al. (2001) [53].

patterns in community structure and to relate them to measured environmental variables including pollutants [42]. Cherai beach supported maximum diversity and abundance of interstitial taxa. Further analysis with the help of available primary data would be carried out to explain the trophodynamics and ecology of the nematodes and harpacticoids of Cherai and Sakthikulangara beaches. 


\section{Conclusion}

Nine interstitial taxa dominated by nematodes and harpacticoids abound the five ecologically vibrant beaches of Kerala. The organic matter in the beaches ranged from 0.01 to 0.745 and the grain size varied from 0.93 to $2.88 \varphi$. Organic matter correlated significantly with coarse sand (Pearson correlation $r=0.651 ; P<0.01)$. The angularity of sediments plays a significant role in the amount of organic carbon adsorbed to the sediments. Total meiofaunal density correlated positively with medium sand $(r=0.38 ; P<0.05)$. Organic carbon, particle size, and dissolved oxygen determined the abundance and distribution of interstitial fauna as per multivariate BIOENV analysis. Diversity index (Shannon Wiener $H^{\prime}$ ) was maximum at Cherai (2.027) indicating the stability of environmental parameters and minimum at Sakthikulangara (1.44) characterized by regular physical changes. The value of nematode/copepod ratio $(N(2 A) / C>10)$ obtained for Sakthikulangara beach indicate disturbed nature of this beach. Nonmetric multidimensional scaling, MDS (stress = 0.08 ), and cluster analysis (similarity profile, SIMPROF test) revealed significant differences in special distribution patterns of various interstitial taxa.

\section{Conflict of Interests}

The authors declare that there is no conflict of interests regarding the publication of this paper.

\section{Acknowledgments}

Priyalakshmi Geetha is thankful to the authorities of Bharata Mata College, Thrikkakara, Kochi, for the assistance and help and N. R. Menon the EU Incolab Grant no. 295092 for the work. They are also thankful for the constructive comments and suggestions of two anonymous referees on an earlier draft of the paper.

\section{References}

[1] P. Kaladharan, D. Prema, A. Nandakumar, and K. K. Valsala, "Occurrence of tarball and waste materials on the beaches along Kerala coast in India," Journal of the Marine Biological Association of India, vol. 46, no. 1, pp. 93-97, 2004.

[2] F. Elaine Albuquerque, A. P. B. Pinto, A. Perez, and V. G. Veloso, "Spatial and temporal changes in interstitial meiofauna on a sandy ocean beach of South America," Brazilian Journal of Oceanography, vol. 55, no. 2, 2007.

[3] M. Baba, "Wave characteristics and beach processes of the south-west coast of India-a summary," in Ocean Waves and Beach Processes, M. Baba and N. P. Kurien, Eds., pp. 225-238, 1988.

[4] S. Creer, V. G. Fonseca, D. L. Porazinska et al., "Ultrasequencing of the meiofaunal biosphere: practice, pitfalls and promises," Molecular Ecology, vol. 19, supplement 1, pp. 4-20, 2010.

[5] T. K. de Oliveira Pinto and P. J. Parreira Dos Santos, "Meiofauna community structure variability in a Brazilian tropical sandy beach," Atlantica, Rio Grande, vol. 28, no. 2, pp. 117-127, 2006.

[6] H.-U. Dahms, S. Chullasorn, N. V. Schizas, P. Kangtia, W. Anansatitporn, and W.-X. Yang, "Naupliar development among the tisbidae (Copepoda: Harpacticidae) with a phylogenetic analysis and naupliar description of Tisbe thailandensis from Thailand," Zoological Studies, vol. 48, no. 6, pp. 780-796, 2009.

[7] T. Yamanaka, D. Raffaelli, and P. C. L. White, "Physical determinants of intertidal communities on dissipative beaches: implications of sea-level rise," Estuarine, Coastal and Shelf Science, vol. 88, no. 2, pp. 267-278, 2010.

[8] J. G. Rodríguez, M. Lastra, and J. López, "Meiofauna distribution along a gradient of sandy beaches in northern Spain," Estuarine, Coastal and Shelf Science, vol. 58, pp. 63-69, 2003.

[9] O. Giere, "Synecological perspectives in meiobenthology", in Meiobenthology: the Microscopic Motile Fauna of Aquatic Sediments, vol. 2nd, pp. 406-416, Springer, 2009.

[10] A. G. Govindankutty and N. B. Nair, "Preliminary observations on the interstitial fauna of the south-west coast of India," Hydrobiologia, vol. 28, no. 1, pp. 101-112, 1966.

[11] K. C. Rajan, Studies on the interstitial fauna of the southwest coast of India [Ph.D. thesis], University of Kerala, 1972.

[12] R. Damodaran, "Studies on the benthos of the mud banks of the Kerala coast," Bulletin of the Department of Marine Sciences, vol. 6, pp. 1-126, 1973.

[13] P. K. Abdul Aziz and N. B. Nair, "Meiofauna of the EdavanaNadayara Paravur backwater system south west coast of India," Mahasagar Bulletin of the National Institute of Oceanography, vol. 16, no. 1, pp. 55-65, 1983.

[14] B. S. Ingole, Z. A. Ansari, and A. H. Parulekar, "Benthic fauna around Mauritius Island, southwest Indian Ocean," Indian Journal of Marine Sciences, vol. 21, no. 4, pp. 268-273, 1992.

[15] Z. A. Ansari and A. H. Parulekar, "Distribution, abundance and ecology of the meiofauna in a tropical estuary along the west coast of India," Hydrobiologia, vol. 262, no. 2, pp. 115-126, 1993.

[16] S. Sajan, T. V. Joydas, and R. Damodaran, "Meiofauna of the western continental shelf of India, Arabian Sea," Estuarine, Coastal and Shelf Science, vol. 86, no. 4, pp. 665-674, 2010.

[17] R. J. Rundell and B. S. Leander, "Masters of miniaturization: convergent evolution among interstitial eukaryotes," BioEssays, vol. 32, no. 5, pp. 430-437, 2010.

[18] O. Pfannkuche and H. Thiel, "Sample processing," in Introduction to the Study of Meiofauna, R. P. Higgins and H. Thiel, Eds., pp. 134-145, Smithsonian Institution, Washington, DC, USA, 1988.

[19] W. Wieser, "Benthic studies in buzzards bay. II, The meiofauna," Limnology and Oceanography, vol. 5, pp. 121-137, 1960.

[20] C. Neira and M. Rackemann, "Black spots produced by buried macroalgae in intertidal sandy sediments of the Wadden sea: effects on the meiobenthos," Journal of Sea Research, vol. 36, no. 3-4, pp. 153-170, 1996.

[21] J. D. H. Wiseman and H. E. Bennette, "Distribution of organic matter and nitrogen in the sediments from the Arabian Sea," John Murray Expedition, vol. 3, 1960.

[22] H. Barnes, Apparatus and Methods in Oceanography. Part I, George Allen \& Unwin, London, UK, 1959.

[23] J. B. Buchanan, "Sediment Analysis," in Methods for the Study of Marine Benthos, N. A. Holme and A. D. McIntyre, Eds., vol. 16 of IBP Handbook, pp. 41-65, Blackwell, Oxford, 2nd edition, 1984.

[24] R. L. Folk, Petrology of Sedimentary Rocks, Hemphil, Austin, Texas, USA, 1974.

[25] J. D. H. Strickland and T. R. Parsons, "A practical handbook of Seawater analysis," in Bulletin of the Fisheries Research Board of Canada, vol. 167, pp. 1-310, 2nd edition, 1972. 
[26] C. E. Shannon and W. Wiener, The Mathematical Theory of Communication, Usbana, University of Illinoi Press, 1949.

[27] E. H. Simpson, "Measurement of diversity," Nature, vol. 163, no. 4148, p. 688, 1949.

[28] E. C. Pielou, Ed., An Introduction to Mathematical Ecology, Wiley-Interscience, New York, NY, USA, 1969.

[29] R. M. Warwick, "The nematode/copepod ratio and its use in pollution ecology," Marine Pollution Bulletin, vol. 12, no. 10, pp. 329-333, 1981.

[30] T. Ganesh and A. V. Raman, "Macrobenthic community structure of the northeast Indian shelf, Bay of Bengal," Marine Ecology Progress Series, vol. 341, pp. 59-73, 2007.

[31] J. W. Nybakken, Marine Biology: an Ecological Approach, Addisoon-Wesley, Boston, Mass, USA, 1996.

[32] P. J. Somerfield, H. L. Rees, and R. M. Warwick, "Interrelationships in community structure between shallow-water marine meiofauna and macrofauna in relation to dredgings disposal," Marine Ecology Progress Series, vol. 127, no. 1-3, pp. 103-112, 1995.

[33] P. S. Meadows and J. G. Anderson, "Micro-organisms attached to marine and freshwater sand grains," Nature, vol. 212, no. 5066, pp. 1059-1060, 1966.

[34] D. McIntyre and D. J. Murison, "The meiofauna of a flatfish nursery ground," Journal of the Marine Biological Association of the United Kingdom, vol. 53, pp. 93-118, 1973.

[35] B. O. Jansson and Quantitative a, "Experimental Studies of the Interstitial Fauna in Four Swedish Beaches," Ophelia, vol. 5, pp. 1-72, 1968.

[36] A. Trevallion, A. D. Ansell, P. Sivadas, and B. Narayanan, "A preliminary account of two sandy beaches in South West India," Marine Biology, vol. 6, no. 3, pp. 268-279, 1970.

[37] B. S. Ingole and A. H. Parulekar, "Role of salinity in structuring the intertidal meiofauna of a tropical estuarine beach: field evidence," Indian Journal of Marine Sciences, vol. 27, no. 3-4, pp. 356-361, 1998.

[38] P. N. Ganapati and G. C. Rao, "Ecology of the interstitial fauna inhabiting the sandy beaches of Waltair coast," Journal of the Marine Biological Association of India, vol. 4, no. 1, pp. 44-57, 1962.

[39] V.M. A. P. Silva, P. A. Grohmann, and C. S. R. Nogueira, "Studies of meiofauna of Rio de Janeiro, Brazil," Coastal Zone, vol. 91, no. 3, pp. 2011-2022, 1991.

[40] C. A. I. Lizhe, F. U. Sujing, Y. Jie, and Z. X. Ping, "Distribution of meiofaunal abundance in relation to environmental factors in Beibu Gulf, South China," Acta Oceanologica Sinica, vol. 31, pp. 92-103, 2012.

[41] G. Mantha, M. S. N. Moorthy, K. Altaff et al., "Seasonal shifts of meiofauna community structures on sandy beaches along the Chennai coast, India," Crustaceana, vol. 85, no. 1, pp. 27-53, 2012.

[42] M. Moreno, T. J. Ferrero, V. Granelli, V. Marin, G. Albertelli, and M. Fabiano, "Across shore variability and trophodynamic features of meiofauna in a microtidal beach of the NW Mediterranean," Estuarine, Coastal and Shelf Science, vol. 66, no. 3-4, pp. 357-367, 2006.

[43] D. G. Raffaelli and C. F. Mason, "Pollution monitoring with meiofauna, using the ratio of nematodes to copepods," Marine Pollution Bulletin, vol. 12, no. 5, pp. 158-163, 1981.

[44] B. C. Coull, G. R. F. Hicks, and J. B. J. Wells, "Nematode/copepod ratios for monitoring pollution: a rebuttal," Marine Pollution Bulletin, vol. 12, no. 11, pp. 378-381, 1981.
[45] P. J. D. Lambshead, “The nematode/copepod ratio. Some anomalous results from the Firth of Clyde," Marine Pollution Bulletin, vol. 15, no. 7, pp. 256-259, 1984.

[46] R. Danovaro, M. Fabiano, and M. Vincx, "Meiofauna response to the Agip Abruzzo oil spill in subtidal sediments of the Ligurian Sea," Marine Pollution Bulletin, vol. 30, no. 2, pp. 133145, 1995.

[47] S. Amjad and J. S. Gray, "Use of the nematode-copepod ratio as an index of organic pollution," Marine Pollution Bulletin, vol. 14, no. 5, pp. 178-181, 1983.

[48] T. F. Sutherland, C. D. Levings, S. A. Petersen, P. Poon, and B. Piercey, "The use of meiofauna as an indicator of benthic organic enrichment associated with salmonid aquaculture," Marine Pollution Bulletin, vol. 54, no. 8, pp. 1249-1261, 2007.

[49] M. Moreno, L. Vezzulli, V. Marin, P. Laconi, G. Albertelli, and M. Fabiano, "The use of meiofauna diversity as an indicator of pollution in harbours," ICES Journal of Marine Science, vol. 65, no. 8, pp. 1428-1435, 2008.

[50] P. Veiga, C. Besteiro, and M. Rubal, "Meiofauna communities in exposed sandy beaches on the Galician coast (NW Spain), six months after the Prestige oil spill: the role of polycyclic aromatic hydrocarbons (PAHs)," Scientia Marina, vol. 74, no. 2, pp. 385394, 2010.

[51] P. J. Somerfield, H. L. Rees, and R. M. Warwick, "Interrelationships in community structure between shallow-water marine meiofauna and macrofauna in relation to dredgings disposal," Marine Ecology Progress Series, vol. 127, no. 1-3, pp. 103-112, 1995.

[52] G. M. Shiells and K. J. Anderson, "Pollution monitoring using the nematode/copepod ratio. A practical application," Marine Pollution Bulletin, vol. 16, no. 2, pp. 62-68, 1985.

[53] M. R. Lee, J. A. Correa, and J. C. Castilla, "An assessment of the potential use of the Nematode to copepod ratio in the monitoring of metal pollution-the chanaral case," Marine Pollution Bulletin, vol. 42, no. 8, pp. 696-701, 2001.

[54] N. Smol, R. Huys, and M. Vincx, "A four year analyses of the meiofauna community of a dumping site for $\mathrm{TiO}_{2}$ waste off the Dutch coast," Chemistry and Ecology, vol. 5, pp. 197-215, 1991.

[55] K. G. M. T. Ansari, P. S. Lyla, S. Ajmal Khan, S. Manokaran, and S. Raja, "Community structure of harpacticoid copepods from the south east continental shelf of India," Proceedings of the International Academy of Ecology and Environmental Sciences, vol. 3, no. 2, pp. 87-100, 2013. 

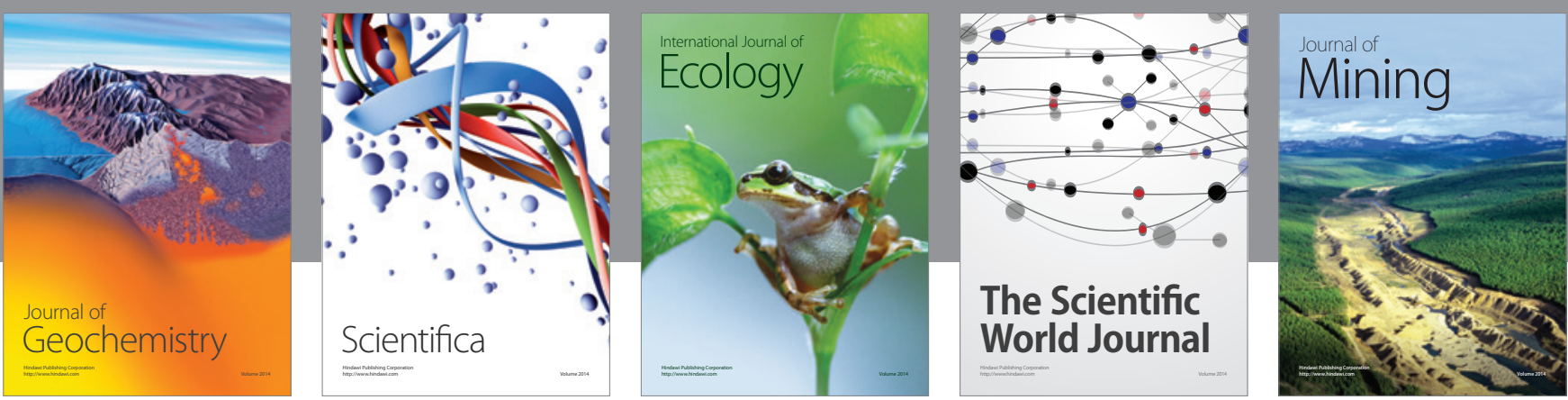

The Scientific World Journal
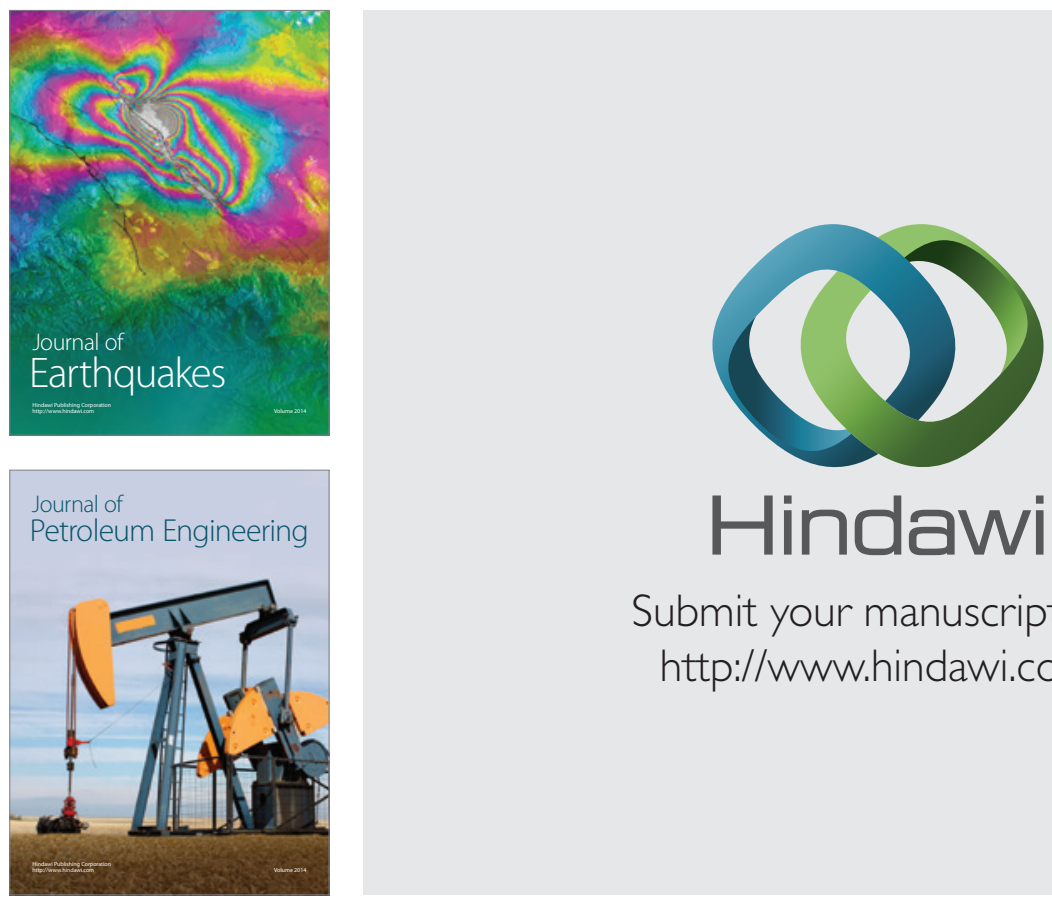

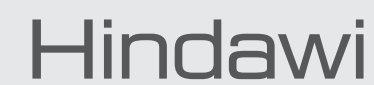

Submit your manuscripts at

http://www.hindawi.com
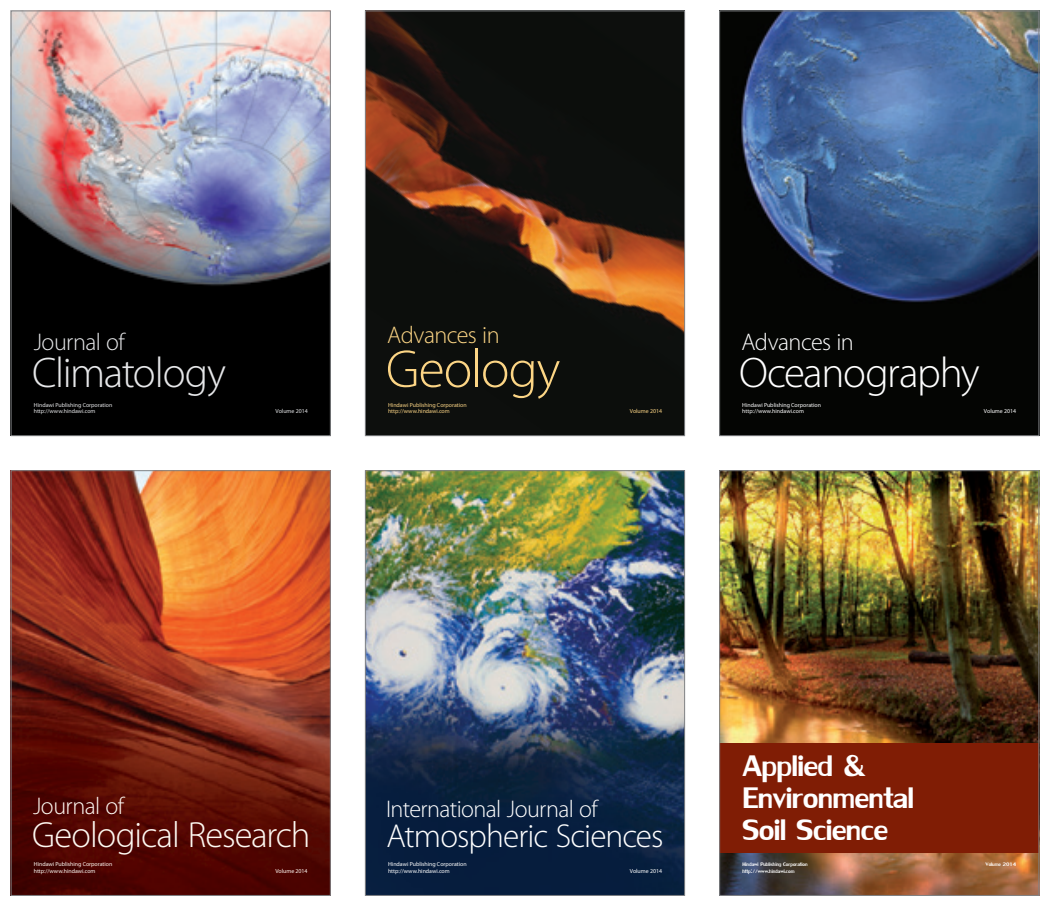
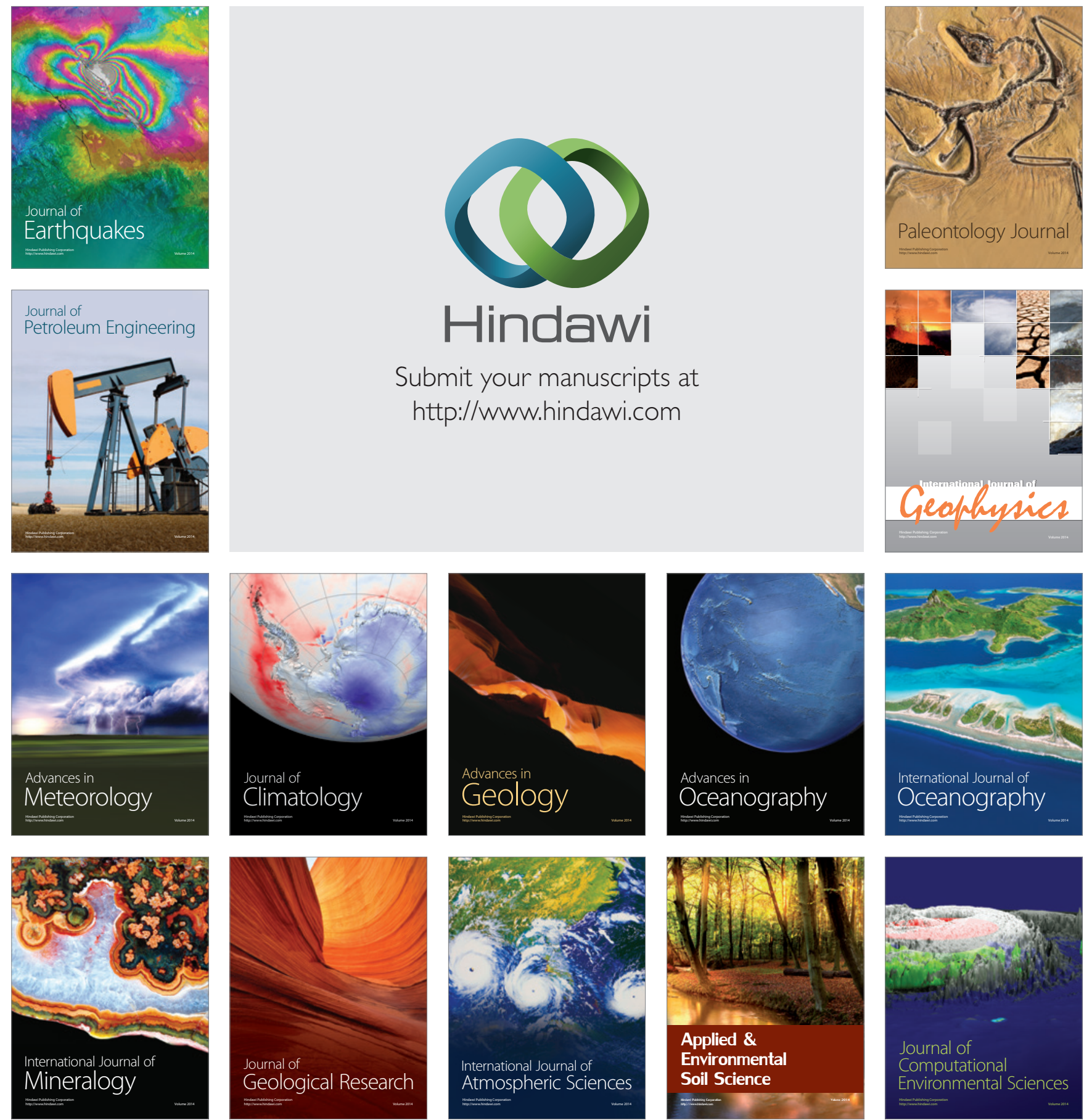